\title{
Touchpoint Management and Interpersonal Communication
}

\author{
Mikael Jensen \\ Correspondence: Mikael Jensen, Division of cognition and communication, University of Gothenburg, Sweden
}

Received: March 22, 2015 Accepted: March 28, 2015 Online Published: March 31, 2016

doi:10.11114/smc.v4i1.1476

URL: http://dx.doi.org/10.11114/smc.v4i1.1476

\begin{abstract}
A touchpoint is anything in time and space with the purpose to temporarily enable sharing of information and minds to be connected. Since we in our time have many ways to get in touch we are starting to pay more attention on how to manage our available touchpoints for the benefit or our relationships and communicative goals. An interpersonal theory of touchpoint management is outlined based on six basic communication premises. Several parameters are described to distinguish between different touchpoints and what they can afford in communicative situations. Touchpoints can be managed in kind and degree. To optimize the choice and use of touchpoints we have to take a lot of factors into consideration. The suggested factors are collected in nine dimensions and three of them are seen as more important: Accessibility (preference and skills), relations and effectiveness (goals). Related theories are discussed and compared in terms of similarities and differences.
\end{abstract}

Keywords: touchpoint, interpersonal communication, communicative tools, intentionality, goals, effectiveness

\section{Introduction}

\subsection{Key Concept and Purpose}

We are used to and expect people in everyday situations to share thoughts and emotions communicating face-to-face but equally possible via the phone or instant messenger. How many ways are there to get in touch with each other and share information? What possible combinations are there? What connection is optimal?

A Swedish high school class is traveling by train to the nearest big city. The teacher has exhorted the students to sit still and be quiet not to disturb the other passengers. Two teenage girls from the class that are sitting beside each other are using their smartphones to listen to music in their headphones. They are not sharing the music in itself but are regularly showing the display of the smartphone, with song information on it, to the friend. The friend is showing recognition or liking by nodding the head. When one of the girls really like what she is listening to she is not just showing the smartphone display but is also moving her whole body. Especially the head. She is miming with the singing in her headphones and repeatedly smiles. The girls are taking turns in sharing music information and liking for a long time during the trip.

In this example there is no oral verbal communication, in fact no oral communication at all. The oral communication would probably not have made much sense since the communicators where listening to music in their headphones. A lot can be said about this example but the most striking aspect is how they share their thoughts and feelings with each other. Based on the context the girls know that they are not to disturb other passengers with music or loud speaking and they know that the friend is listening to music so they have to adapt their communication to get through. To share relevant information they use their smartphone displays, verbal but not oral, and they use nonverbal body movements and expressions. The girls show each other understanding and give feedback by nodding and smiling and other movements. To focus on the most interesting aspect of this scene the phenomenon needs a useful and suitable term. The term chosen is touchpoint.

A touchpoint is defined as anything (an area, a point/set of points or a surface/set of surfaces) in time and space with the purpose to temporarily enable sharing of information and minds to be connected (Jensen, 2016a). It is important to state that a touchpoint is not synonymous with medium because it can rely on several media. It is not the same as a technological device since we often get in touch with each other without devices and sometimes use more than one at the same time. A device like a smartphone also has different ways to get in touch with others via a phone call, SMS, e-mail, video call or an image-based message (cf. Norman, 2011). It would not be fair to equate touchpoint with the term channel since a touchpoint can rely on one or several channels. A touchpoint is not the same as software like Skype 
that has at least three functions (video call, phone call and chat) because all can be used as a touchpoint separately but also as one touchpoint in parallel (e.g. phone call and chat together) in an integrated way.

The purpose of this paper is to outline a theory on touchpoints and touchpoint management in interpersonal communication. To make this possible we have to clarify the basic communication premises that make the foundation of the theory. We also have to distinguish the affordances and characteristics of different kind of touchpoints. To be able to manage touchpoints in kind it has to be possible to have at least two alternatives to choose from. It might also be possible to manage touchpoints in degree but that is not the focus of this paper (but will be explained). Touchpoint management is the attempt, in every interpersonal communication situation, to optimize the connection between minds and the sharing of information. Optimization is primarily about effectiveness and secondarily about other aspects/factors. The core of the theory is presented as nine dimensions of touchpoint management for optimization. No interpersonal communication theory so far is including a touchpoint but there are other theories that center on communication technology devices, "channels" or "media". To delimit and highlight the advantages and specificity of this theory it will be compared with other theories in an ending discussion.

\subsection{Basic Interpersonal Communication Premises}

The foundation of the theory outline is presented as six basic communication premises: A-F. They are all related to touchpoints in some way.

A. Human communication is basically about connecting minds (intentional beings) (cf. Peirce, 1998; Krauss \& Morsella, 2014). Since minds are not directly connected we have to find ways to get in touch with each other.

B. Human beings are innately highly social minded and socially oriented (Gazzaniga, 2008; Forgas, Williams \& Wheeler, 2001; Forgas, Vincze \& László, 2014; Trevarthen \& Aitken, 2003; Goldman, 2006; Dunbar, 2007a; 2007b; Whiten, 2007). This can be recognized by:

- the preference to direct attention towards human voices, shapes that look like human bodies, human movements and especially towards faces (Trevarthen \& Aitken, 2003; Kendon, 2004; Proulx, 2007; Delafield-Butt \& Trevarthen, 2013).

- the ability to imitate (Meltzoff \& Prinz, 2002; Tomasello, 2003; Hurley \& Chater, 2005) suggesting that we are developed with the capacity to pick up other beings behavior (and intention) and reproduce these behaviors with a high degree of accuracy.

- the fact that we form relationships that are unique and affect our communication (Knapp \& Vangelisti, 2009).

This social mindedness makes us want to get in touch with other human beings and find ways to do it. Some prefer communication face to face while others might prefer computer-mediated communication but both are socially oriented. The relationship affects our choices for how to get in touch with each other.

C. Behavior, in general, and communication, as a particular form, is basically intentional (Grice, 1957; 1969; Searle, 1969; Kendon, 1981; Meltzoff, 1988; 1995; Sperber \& Wilson, 1995; Bratman, 2014; Gibbs, 1999; 2001; Bandura, 1997; 2001; Tomasello, 2005; 2008; Namy \& Waxman, 2005; Sabbagh \& Baldwin, 2005; Baldwin, 2012; Kashima, Klein \& Clark, 2007; Stephan et al., 2008; Iacoboni, 2009; Jackendoff, 2009; Matsumoto, 2010; Bangerten \& Mayor, 2013; Delafield-Butt \& Trevarthen, 2013; Liebal et al., 2014). An intention can be described as a means-ends-relation (Tomasello, 2003; Tomasello et al., 2005; Meltzoff, 2005; Carpenter \& Call, 2007, cf. Norman, 1988). To attain a specific goal we tend to use a specific means that very well goes together with that specific goal (Wilson, 2010). Like a lock-and-key-relation. A goal-means-relation is the typical combination but not the only one (se about flexibility below) and it also is the easiest way to recognize other individuals' intentions. This implies that:

- we assume by default that others communicative acts are intentional (Jackendoff, 2009; Zegarac, 2011) and we are intention-readers that try to find out what others intend (Meltzoff, 1995; 2005; Decety \& Chaminade, 2005; Tomasello, 2005; Tomasello \& Carpenter, 2005; Malle, 2005; Namy \& Waxman, 2005; Berger, 2010; Baldwin, 2012; Goldman, 2013).

- we are goal-directed in our communication (Bandura, 2001; Berger, 2007; 2008; 2010; Wilson, 2007; 2010; Hollingshead, Costa Jacobsohn \& Beck, 2007; Dillard, 2008; Canary, Cody \& Manusov, 2008).

- we form plans for how to reach our goals (Berger, 2007; 2008; 2010; Dillard, 2008) that includes possible and optimal means.

In our plans for how to attain the communicative goal we also need to include how to get in touch with the co-communicator and what might be the optimal way to get in touch and stay in touch (i.e. to attain the goal). Effectiveness is the key.

D. Human communication has often been defined as "a process in which participants create and share information with one another in order to reach a mutual understanding" (Rogers, 2003, p. 5; cf Shannon \& Weaver, 1949; Bateson, 
1972/2000; Wilden, 1987; Kashima et al., 2007; Allwood, 2008; Stephan et al., 2008; Salem, 2009). The human being has also been described as an information processing creature (Newell \& Simon, 1972; Gardner, 1985; Greene \& Dorrance Hall, 2013). Rather than describing communication in terms of a hardcore information processing system, intentional beings as well as the communication process is considered to involve, handle and share information in some sense. This is especially relevant when discussing perception, attention, schema and decision-making (Malle, 2005; Young, 2011). As a consequence of humans being information processing creatures we form perceptions, draw inferences and make decisions based on the information available:

- too little information will make us engage in information seeking activities (Berger \& Calabrese, 1975; Afifi \& Weiner, 2004; Afifi, 2010b; Knobloch, 2008; Gottlieb et al., 2013).

- too much information, information overload (Norman, 2011), will make the information processing difficult caused by so called bottleneck effects (Marios \& Ivanoff, 2005) and limited cognitive capacity (Greene \& Dorrance Hall, 2013). We have to focus on the most relevant information as well as on the least disturbing/confusing information (Afifi \& Weiner, 2004; Wharton, 2013).

If we get too much or too little information or anticipate that the information might be scarce or overwhelming we have the possibility to choose the way we get in touch with each other and how to manage the present contact. Optimal ways can be learned.

E. Human beings are highly flexible compared to other species (Deacon, 1997; Hauser \& Santos, 2007; Griebel \& Oller, 2008; Stephan et al., 2008). Most species have primarily fixed behaviors or expressions for each function or intention. The step away from the fixed relation is sometimes called means-ends dissociation (Tomasello \& Carpenter, 2005; Call, 2008). Several possible means can be used to attain a specific goal (Stephan et al., 2008; cf. Afifi, 2010a, 48). It can also be described in the reversed way: one means can be used to attain several possible goals. It is a principle of functional freedom that infants and most animals don't fully possess. This has also been described in slightly different terms (Griebel \& Oller, 2008): signal flexibility (flexibility in available means) and functional flexibility (flexibility in possible functions or goals). Functional flexibility is more complex and difficult. High flexibility, of both kinds, have made us symbol users and symbol minded (Deacon, 1997; Namy \& Waxman, 2005; Stephan et al., 2008) as well as multimodal communicators (Allwood, 2014). This implies that:

- we have a high flexibility in using and combining signs (Greene, 2015).

- we can choose how to combine verbal and nonverbal communication.

- we can choose between oral or written symbolic communication.

- we can choose means for how to deliver the message.

- we can choose means for how to attain the main goal.

When we want to deliver a certain message we have the ability to select between a number of possible and optimal alternatives in how we get in touch with others and manage the ongoing conversation.

F. Human beings have a high ability to inhibit mental processes and behavioral acts (MacLeod, 2007). From neuroscience we know that covert speech (and singing) is inhibited overt speech (and singing) (Brown et al., 2004). The ability to imitate is always present (Tomasello, 2003) but we have, rather early in our development, the choice to inhibit imitative behavior (Kinsbourne, 2005; Hurley, 2005; Goldman, 2013). Normally we express what we feel inside to share it with others. Eventually, there are some situations when it is better to not share our emotions. One way is to inhibit (not express anything) and another way is to mask (express an emotion that is incongruent with the inner state which also includes inhibition of the congruent emotion) (Ekman \& Friesen, 1967/1981; Andersen \& Guererro, 1998; Matsumoto \& Hwang, 2013). When we try to take another individuals perspective towards a certain phenomenon we temporarily have to inhibit our own perspective and our own beliefs and desires (Goldman, 2006; MacLeod, 2007). This is not always the case but especially in communication learning, in new communicative situations, when the communication (in form or content) is unexpected and when we experience a communication problem (Sabbagh \& Baldwin, 2005). When we lie well we have to inhibit the truth both in mind and in action.

Thinking, experiencing, expressing and acting are regulated by our ability to inhibit equally much as our ability to express/exhibit. Both these abilities are affecting us when we communicate and when we plan for how to attain our goals. To get in touch with someone in particular we might consider that other person's preference and not just our own. We can take the other ones perspective in how he or she will perceive the message if it is presented in a certain way. This will affect how we choose to get in touch with the co-communicator. Our own interest in delivering emotions or to deceive will probably affect the choice of how we get in touch. It is easier to lie, at least for most deceivers, without eye contact. It is also easier to express emotions in certain ways (with certain touchpoints). 


\subsection{Affordances and Properties of Touchpoints}

The term touchpoint originally comes from the field of business and marketing communications (see i.e. Elias, 1999; Spengler \& Wirt, 2009; Dhebar, 2013; Lee, Chung \& Nam, 2013). In marketing, customer touchpoints are defined as a brand's points of customer contact, and many studies in the field of marketing communications have attempted to identify and study these customer touchpoints (Ansari \& Riasi, 2016; Riasi \& Amiri Aghdaie, 2013; Riasi \& Pourmiri, 2015). In this context, as presented in this paper, the term gets a slightly different and more general meaning. The properties of touchpoints can be determined by a number of parameters. Every touchpoint has a certain affordance. It is the affordance that determine what we can accomplish with the touchpoint or what we believe can be accomplished (Jensen, 2016b).

The content of one mind to another is carried from one communicator to another communicator via one or several media. A medium means the physical particles or waves that travel from one communicator to another or from the sending communicator to a sender device, from the sender device to the receiver device and from the receiver device to the receiving communicator. The typical particles and waves are chemicals that we detect as odors, light waves (photons) that cause visual sensations or travel in optic fibers, sound waves that cause auditory sensations, electrons that travel in cables, radio waves and micro waves that travel in the air from one device to another. The term media is often used synonymously to the technological devices that we use every day like TV, radio, telephones, newspapers and computers (see Perrin \& Ehrensberger-Dow, 2010). In this case they are separated because face-to-face communication wouldn't be possible without at least one media. Face-to-face communication requires air to allow chemicals, light waves and sound waves to travel to activate the distal senses (Gibson, 1986). It is problematic though to say that air is a medium, like for example Gibson does, since a dark room contains air but no light waves. It is better to focus on the particles and waves that are mobile and actually do something with our senses. The proximal senses require direct contact with the source as is the case when one person touches another person. The skin, on a cellular (biochemical) level, is therefore also a medium. This first parameter is based on the kind and number of media that a touchpoint involve.

It would be reasonable to conclude that every touchpoint has to have a size. In some cases it is easy to determine the size of a touchpoint like in the case of a smartphone display or a post-it note but more difficult when the touchpoint is the area in between two individuals communicating face-to-face. When two human beings embrace in a hug the physical contact area has a rather demarcated touchpoint size but as soon as the individuals take a step back it becomes vaguer. The larger touchpoint can probably transfer/transport more information.

A touchpoint exist in time. It has duration. In some cases, like in face to face communication, the touchpoint only exist as long as you hear and see the other communicator. In other cases, like a post-it note on the refrigerator door, the physical manifestation of the touchpoint exist even when no one perceives it but it doesn't come to use, or become activated, until someone (the intended receiver) perceives it. A written message often has the advantage that it can be re-read while speech dissolves as soon as the sound waves have passed the receiver (Young, 2011).

A touchpoint has a degree of closeness in time. A high degree of closeness in time means that there is no delay from the production of the message to the reception of the message. It can also be called synchronicity. The highest degree possible can be found in face-to-face interaction. A low degree of closeness in time is found when there is a long delay between the production of the message and the reception of the message. This can be found in traditional mail writing. The delay can in some cases be weeks (Allwood, 2014; cf. Norman, 1999).

A touchpoint has a degree of closeness in space. A high degree of closeness in space means that the co-communicators are in the same location, most typically in each other's personal or intimate zone (cf. Hall, 1969). A low degree of closeness in space can be found when two persons are far away from each other. A long distance phone call, chat or e-mailing are examples of this (Allwood, 2013). Bolchini and Shirong Lu (2013) calls closeness in space co-located and distance in space dislocated.

To be able to communicate an agent needs at least one sense modality, most often the visual or auditory modality, to receive the communicated message (Partan \& Marler, 2005; Paivio, 2007; Allwood, 2008; 2014; Gurban \& Thiran, 2010; Walker-Andrews, 2012; Liebal et al., 2014). A touchpoint can offer a maximum of sense modality information at the same time, that is at least five senses, for example in intimate communication. Touchpoints like phone calls or post-it notes rely on only one sense modality. Sense modalities are sometimes called input modalities (Ruiz, Chen \& Oviatt, 2010).

Modes of production (Kress, 2010; Cobley, 2010; Gurban \& Thiran, 2010), production modalities (Partan \& Marler, 2005; Allwood, 2008; 2014; Burgoon, Guerrero \& Manusov, 2011; Liebal et al., 2014) or output modalities (Pandzic, 2010) make it possible to create and send a message. A touchpoint can afford information from one or several production modalities. One production modality could be speech or writing. Other production modalities could for example be gestures, voice quality, facial expressions, odors, touch, posture, sound effects, photographs, maps or 
diagrams. Some touchpoints do not offer information from more than one production modality.

A touchpoint can afford a certain degree of intensity (see Norris, 2004). Amplitude, for example a strong voice, or salience, for example a bright color, can in itself be intense. Some touchpoints cannot offer high intensity (e.g. a post-it note) and some touchpoints can be perceived as too intense (someone shouting in your ear).

A touchpoint can afford a certain degree of complexity (Norris, 2004; cf. Norman, 2011). How complex the message is, or parallel messages are, is ranging from simple (or low) to high complexity. Some touchpoints can offer high complexity while others offer low complexity. Redundancy and nonredundancy (Partan \& Marler, 2005) are components of the complexity. High redundancy is often related to low or mid complexity while nonredundancy, several production modalities with (in themselves) different meaning are used, most often implies high complexity.

A touchpoint can be unidirectional or bidirectional (Holmes, 2005). A letter, a podcast or any kind of recording is unidirectional. From sender to receiver. A telephone is bidirectional and offers co-communicator interaction.

A touchpoint can offer different degrees of sequence, turn management and feedback (see Allwood, 2008; 2014). It is not just easier but also desirable to structure a face-to-face, video call or phone call conversation in a sequence with turns compared to a handwritten letter correspondence. It is not as disturbing if two persons happen to write a letter to each other at the same time as it would be if two individuals are talking at the same time. Some touchpoints can offer synchronized feedback (e.g. face-to-face and phone call) while other touchpoints only can offer delayed feedback or no feedback (notes and letters). With no feedback it is more difficult to know if the co-communicators understand each other well or at all. Feedback offer smoothness to the synchronous interaction (Jensen, 2015a).

To determine the properties and affordances of various touchpoints they can be positioned on the following parameters:

- Media parameter (type and number)

- Size parameter

- Duration parameter

- Degree of closeness in time parameter

- Degree of closeness in space parameter

- Sense modality parameter

- Production modality parameter

- Intensity parameter

- Complexity parameter

- Directionality parameter

- Sequence, turn and feedback parameter

\section{Touchpoint Management -Components of an Outlined Theory}

\subsection{Managing Touchpoints in Kind}

A touchpoint is anything that makes two individuals get in touch and share something (information). It can be face-to-face, a video call, a phone call, an e-mail, a message board or a post-it note. If there is more than one option we have the opportunity to manage the touchpoint in kind. We can manage it by choosing one way over another. When we have at least two options it is also possible to combine them. A touchpoint can mainly be face-to-face but also include the use of, for example, a smartphone to show pictures on the display. In many supermarkets, at the checkout, they have displays giving information to the customer about the price of each product and also the sum that the customer is supposed to pay. Simultaneously the cashier is telling the customer the sum to pay. This means that they have standardized an integrated touchpoint, partly to create redundancy (both visible and audible information). In this case it is an integrated touchpoint compared to a single touchpoint only using one means. An integrated touchpoint is based on what could be two (or more) single touchpoints separately. A touchpoint can also be serial if the conversation for example starts with an e-mail and moves on to a phone call.

Two seemingly similar touchpoints can be distinguished as different kinds based on the parameters above. (1) One communicator is talking to another communicator with no barriers in between them. (2) One communicator (e.g. a receptionist) is talking to another communicator (e.g. a client) with a counter and a glass shield in between them (this kind of touchpoint is often used in hospital receptions, police receptions, customs and banks). These two situations that normally would be called face-to-face communication actually employ two kinds of touchpoints with different affordances. The reduction in used media in the second case is also affecting the possibility to receive information to only two sense modalities. You can hear and see each other but you can't touch, smell or taste each other. The degree of closeness is a little lower in the second case and the intensity might also be reduced (even a strong voice can be perceived as normal behind the glass).

In some cases, for example in formal situations or when there is some kind of risk, it can be an advantage to use a 
touchpoint including a barrier. In other situations we have not chosen it. A person that is driving a car and stops the car to let a walking person pass gets a thank you nonverbally. There is an obvious barrier between the driver and the pedestrian but they can still share the thoughts and feelings on their minds. That is also a kind of touchpoint just as when a person behind a window is waving to someone outside. It has happened that a person outside is calling (with the phone) the person inside. They can see each other and because of the phone they can also hear each other. This approach to communicate is by way of an integrated touchpoint.

\subsection{Managing Touchpoints in Degree}

A touchpoint can offer a lot of information being exchanged. Just because the touchpoint affords it doesn't mean that we will use it to its full potential. Just because you can hug and kiss someone that you are in a conversation face-to-face with doesn't mean that you will do it. The situation may inhibit it, the relationship may inhibit it or the topic may inhibit it. Sometimes, on the other hand, the touchpoint may be limited in its affordance but we do what we can to express what we want to share. A video call does not offer hugs and kisses but we try to express the underlying emotion in other ways. Emoticons may be one example. It doesn't involve as many sense modalities but the message may get through anyway.

A person has just received the news that he/she got a promotion. When he/she gets home and no one is there he/she writes a note to his/her partner telling the good news and then leaves. A way to manage the touchpoint in degree could be to also draw a smiley on the paper. Instead of small letters he/she can write the message in capital letters to make it a little bit more intense.

There are many ways to manage the touchpoint in degree once you have selected touchpoint in kind or when it seems that you only have one choice at hand. Our understanding of the touchpoint, learned skills and our flexibility supports this.

\subsection{Touchpoint Optimization}

The first three basic communication premises, A-C, are to a high degree determining how a communicator will try to optimize the touchpoints. They primarily affect the if and the why people get in touch. The three following basic communication premises, D-F, will to some extent affect the management of kind and management of degree. All premises will affect how people get in touch with each other.

- The first basic communication premise will suggest that we try to create any kind of touchpoint rather than none.

- The second basic communication premise will suggest that we will prefer a touchpoint that give an experience of another intentional being. The second premise will also suggest that the current relationship or the desired relationship will affect the choice of touchpoint.

- The third basic communication premise will suggest that the intention or specific goal that a communicator wants to share/achieve will affect the choice of touchpoint in kind and also in degree. Goal-directed communication implies effectiveness (to be successful in attaining the goal).

- The fourth basic communication premise will affect the choice of touchpoint in kind if the information is, or is anticipated to be, too limited or too overwhelming and affect in degree to get the right level of information.

- The fifth basic communication premise will affect the choice of touchpoint if it doesn't fit, or to better fit, the communicative goal or the relationship. The communicator might be creative to manage the touchpoint in kind and/or degree. This premise will also affect our need to use the right combination of production modalities.

- The sixth basic communication premise will affect the choice of touchpoint in kind and the management of the touchpoint in degree based on the receivers abilities, preferences and needs. It can also regulate your choice of touchpoint based on mental energy levels. A surplus of energy increase the possibility to inhibit one's own mental activities while a low energy level will make the inhibition difficult (cf. MacLeod, 2007). Some social situations demand inhibitory control and these situations might or should be avoided when tired. To be able to be at home with low demands on inhibitory control and still be in contact with friends via communicative tools is rather easy also for the tired one.

Based on the six premises and what different touchpoints (single, serial or integrated) can afford there are nine dimensions that will affect the communicators in how they manage the touchpoint in their attempt to optimize the touchpoint and the quality of the contact. The first five dimensions are working like a fundamental rule that generally affect us most but they can be altered or ruled out by the following three dimensions that might be more situation specific. This means that, for example, relations and (sociocultural) environments can overrule other factors/dimension of influence. The most specific dimension, effectiveness, determines the touchpoint management. In the end, if the goal can't be achieved, anticipated before or inferred during the contact, this rules out all the other dimensions and eliminates or inhibits the connection for the present purpose. There is no use to speculate about what affect other dimension can have if the goal can't be reached. To achieve the goal the ninth dimension will overrule or modify the previous ones, up 
to the limit of possibility, if necessary.

\subsubsection{Accessibility}

When we want to get in touch with someone we can only choose between accessible options. Accessibility is affected by a number of factors:

a) the actual means that are at hand ([Holmes, 2005] I don't own Skype or a message board, or the person I want to share information with is not present [Lo \& Lie, 2008]; e.g. extraverts are more likely to own and use a smartphone than introverts [Lane \& Manner, 2011]),

b) the means that can be handled with the necessary skill ([Holmes, 2005; D'Urso \& Rains, 2008] If I haven't learned how to use Skype I wouldn't try even if I own it when an important goal is at stake, but if I am skilled I can stretch the limits of its functionality and be flexible/creative),

c) the means that are operating (the ones I have can be low in battery or have a bad connection [Lo \& Lie, 2008]),

d) the means preferred ([Walther, 2011; Ledbetter, 2015]we are often driven by habits and familiarity [Jensen, 2009]),

e) the number of touchpoints regularly used by an individual or dyad ([Jensen, 2016a] people that have access to and regularly use many touchpoints do that independent or with a limited influence of the situation while individuals that have the habit of only using a few touchpoints do that independent or with a limited influence of the situation),

f) personality traits (introverts prefer technological devices over face-to-face while extraverts prefer face-to-face as the first choice [Jensen, 2015b; 2016b]). This should be even truer among individuals that suffer from communication apprehension that is a combination of introversion and neuroticism [McCroskey \& Beatty, 1998]).

\subsubsection{Synchronicity}

A need of synchronicity will affect the options available and rule out options that can't afford closeness in time. To get fast feedback you need synchronous means but to be able to think things through may attract slower means like mail or e-mail.

\subsubsection{Co-location}

If closeness in space is necessary (because of the need of immediacy and maybe touch) the available means will drastically be reduced. Face-to-face interaction (without barriers) is the first choice.

\subsubsection{Complexity}

If you want to allow or need a high degree of complexity, multimodal means (e.g. face-to-face or a video call) or a written report are good choices (Norman, 1999). The need for common ground/knowledge is greater when the content is more complex and this is what we normally try to achieve with nonverbal means in face-to-face interaction (Bavelas \& Gerwing, 2007). Common knowledge (if not already there) can also be achieved with extensive written correspondence. Non-redundancy (e.g. voice and image) or other grounds for complexity can be served by integrated touchpoints (cf. Watson-Manheim \& Bélanger, 2007). A high level of expressivity (complex emotions) might demand a face-to-face connection. This is what most people prefer (Puccinelli, 2010). Extraverts are recognized by their expressive behavior (Oberzaucher \& Grammer, 2008; Jensen, 2016b) and their need for social (face-to-face?) stimulation (McCrae \& Costa, 2006). This suggests that touchpoints that afford complexity suits them better.

A large computer screen can offer more visual details than a small smartphone display, thus the former can afford a higher complexity (Reeves \& Nass, 1996). If you prefer a low degree of complexity short written messages are better means. If you want to lie to someone high complexity connections like face-to-face makes it easier to detect at least one of the revealing cues (Frank \& Svetieva, 2013). People that know this will probably choose a touchpoint with less modalities (at least avoid face-to-face).

\subsubsection{Intensity}

Strong emotions might demand touchpoints that afford intensity. When we are really happy, angry or sad we need certain means to express this. A sentence in a SMS saying "I am so happy" together with a smiley is not near the intensity that a face-to-face connection can offer. A phone call will come a bit closer. The intensity of real anger face-to-face might be so strong that some people want to avoid it (especially individuals high in neuroticism [Jensen, $2015 \mathrm{~b} ; 2016 \mathrm{~b}])$. It is easier to express anger face-to-face for most people but harder to avoid the intensity of it for the receiver. Sensitive persons will try to get messages via means that afford less intensity. With means that afford less intensity it is still possible to manage the intensity in degree by using capital letters (I AM SO ANGRY) or bold face to emphasize parts of the content. A large image (on a computer screen) is more intense than a small image (on a 
smartphone display). Standing close, in a face-to-face situation, is more intense than standing at a distance (Reeves \& Nass, 1996).

\subsubsection{Control}

Control is primarily referring to the goal and information rather than the conversation and relation. Verbal communication is generally easier to control (whether to say/write something, what to say/write and when to say/write it) compared to gestures, facial expressions and body odors (Allwood, 2008). In real-time conversations (typically face-to-face, video call or phone call) we sometimes say things that we regret, or we stutter. Once it is out in the open for others to perceive, it can't be canceled. Speech in real-time can't be edited. Communication in written form can be edited. We can erase words or phrases that we are not satisfied with and rewrite it. We can read it through before sending it (de Mooij, 2014). Individuals that score high on neuroticism have a tendency to worry and they would often like to control their messages to avoid inconvenience. Individuals that score high on conscientiousness prefer to have things in order and to control what they say, write or do is one way to keep life organized.

Synchronous means might be complex and intense but the content is less controllable than a written source (Young, 2011). If you want to check the information more than once, have proof for what someone has communicated, you will prefer a written source (mail, e-mail, report). If you want to have a high degree of control over the information it is better to use storable means. This is the standard way for some individuals (Lane \& Manner, 2011), in some organizations (Miller, 2015) and in some cultures (de Mooij, 2014). If you want to avoid to be controlled (by others) it is better to use non-storable means. Attempts to deceive are easier if others can't control the content. It would thus be better to avoid storable means. This might be why deceivers slightly prefer a phone call (Walther, 2011) that is less revealing than face-to-face and less controllable than written sources.

It might be important to be able to choose the tempo/pace of the conversation to avoid too much information or a risk to miss the main goal (Sheer, 2011). As suggested above, inhibitory control is more energy consuming and can thus be affecting the choice of touchpoint. If you can't control yourself (tired, hungry or ill), it is better to use less demanding ways to get in touch. On the other hand, some touchpoints can offer control as anonymity (Holmes, 2005). Identity alteration is much easier when using computer-mediated communication.

\subsubsection{Relations}

If you know a person well you also know that persons accessible means and preferences. To know that a person have access to or prefers a certain touchpoint might affect your choice in the first place if you want to get in touch with that person. Your own level of empathy (or trait agreeableness) can be a determining factor in your choice if you base your choice of touchpoint on your own preferences, the goal of the contact or your co-communicators preference. An even stronger influence is power. If the co-communicator has more power than you, you will probably adapt to the powerful persons preferences (cf. Goldsmith, 2008; Giles \& Soliz, 2015). If you have more power than your co-communicator it is more up to you what to choose. The level of mutual trust between the co-communicators may affect the choice of touchpoint (Lo \& Lie, 2008). When the level of trust is low it is more important to use a touchpoint that allow high complexity, high intensity, synchronicity and co-location. When the level of trust is high the choices can vary more.

It has been suggested from previous research in professional settings that private conversations more often, during worktime or during lunch breaks, use face-to-face as a touchpoint before other options (Jensen, 2015b; 2016a). To get to know someone or strengthen the relational bonds at work is best done face-to-face (Watson-Manheim \& Bélanger, 2007). In private situations when you are less dependent on the other individual, face-to-face is of lesser value to initiate or strengthen a relationship (see Walther, 2008). Professional dyads that spent a lot of time communication about work-related stuff have the tendency to use many different touchpoints while professional dyads that spend little time communicating about work also use a low number of touchpoints (Jensen, 2016a). Another, similar, way to put it is that people that know each other well use a higher number of touchpoints to communicate with each other compared to people that don't know each other well (Ledbetter, 2015).

\subsubsection{Environmental Factors}

Both the physical and the sociocultural environment may have a strong influence on the management of the touchpoint. A dark environment restricts the available means. Face-to-face communication is definitely possible but one sense modality and several production modalities are reduced. An environment with physical barriers (like in prison visitor rooms) reduces both sense modalities and production modalities. A very noisy environment will delimit the possibility of speech and therefore encourage other means that don't rely on the auditory sense. If the goal of the conversation can't be achieved because of the limitations in the physical environment it simply has to wait until the communicators can get in touch under different circumstances.

A sociocultural environment based on social/cultural rules can delimit certain touchpoints. In a library, at least in certain 
areas, it might be better to communicate via text-based means. In most classrooms smartphones and similar devices are forbidden and therefore can't be used. In the example with the two girls, that were asked to be silent on the train, they solved the situation by combining means into an integrated touchpoint. Some environmental factors can be overcome with some creativity. Environmental constraints may increase the need for control. If we can't control the environment we will try to control ourselves and our outputs.

From another angle, the use of certain touchpoints in a group will be a part of the environment (Holmes, 2005) and in that way influence others use.

\subsubsection{Effectiveness}

The reason why you get in touch with someone is that you have something specific in mind that you want to share. Your goal and what surrounds it (means and plans) is affecting more exact and strong than any other factor or dimension if you are going to choose a touchpoint at all and if you are going to choose a single, serial or integrated touchpoint. The goal and your understanding of the goal help you to decide what means to use. If you have chosen one touchpoint and realize that it can't help you achieve your goal you might choose another touchpoint that better suites the attainment of your goal. A serial touchpoint or an integrated touchpoint might be just the right way.

Effectiveness is about attaining your goal. If you attain your goal you have been effective and if you don't attain your goal you have been ineffective. Your goal determines in the end if your choice of touchpoint (no touchpoint, single touchpoint, serial touchpoint or integrated touchpoint) was successful. In some situations and for some individuals goal attainment is important but in some other situations and to some other individuals goal attainment can seem to be insignificant. Effectiveness is desired in the first cases and therefore will affect the touchpoint management to a higher degree. Based on this we all can learn touchpoint management (both in kind and degree) and touchpoint optimization if and when effectiveness matters.

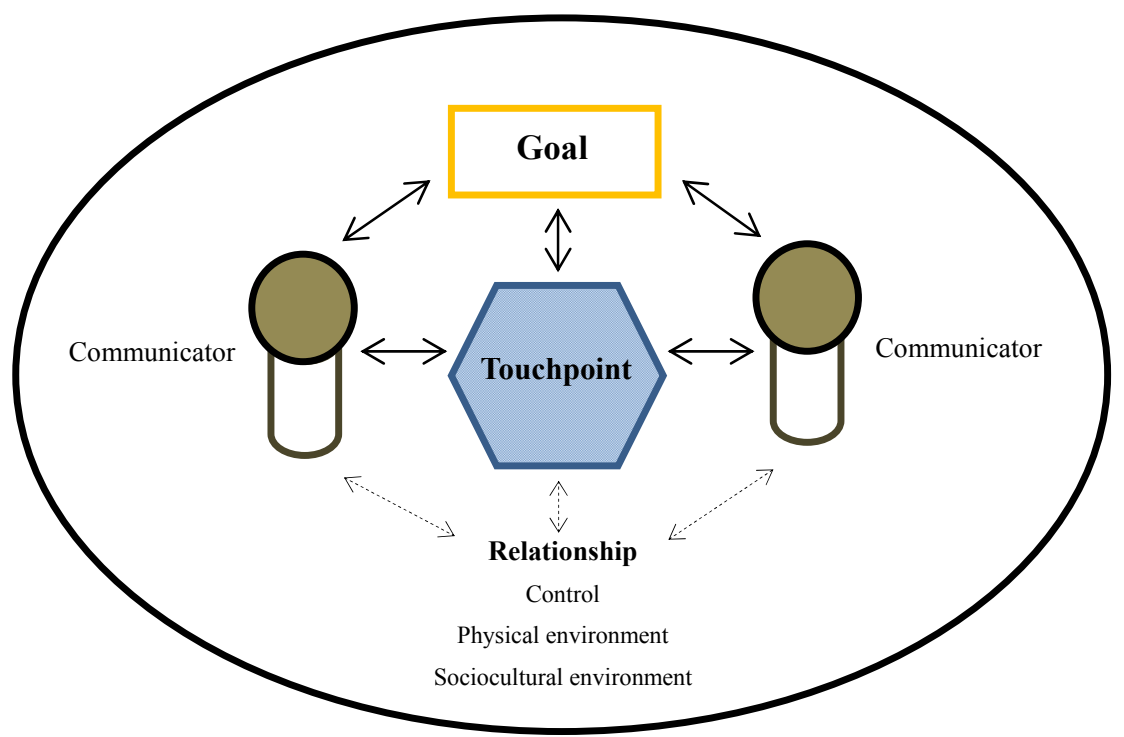

Figure 1. How the touchpoint is interrelated to some other central components. The goal and the relationship are affecting the management of the touchpoint.

\section{Discussion}

The touchpoint management theory is basically an interpersonal theory and should be considered as such in this paper. It is possible though to use the parameters and dimensions to analyze communication on any level. Three of the dimensions stand out as more important: Accessibility (access, skill and preference), relations (the dyad affects your choices [Ledbetter, 2015; Jensen, 2016a]) and effectiveness (you want to achieve your goal). The theory is situation and goal driven which means that a lot of factors have to be considered but in the end it is about what you want to achieve and what you can achieve that matters.

There are six aspects of communication that are recognized in most theories (and textbooks): the message, the communicator(s), the dyad (the relationship), the interaction, the context and the medium/technological device. Some theories focus on one of these factors and some few theories focus on almost all aspects (see Allwood, 2008; 2014). The present theory is focusing on the touchpoint, a seventh aspect, and it relates to most of the other six aspects. This can 
best be shown in a comparison with other theories that try to handle similar communication phenomena.

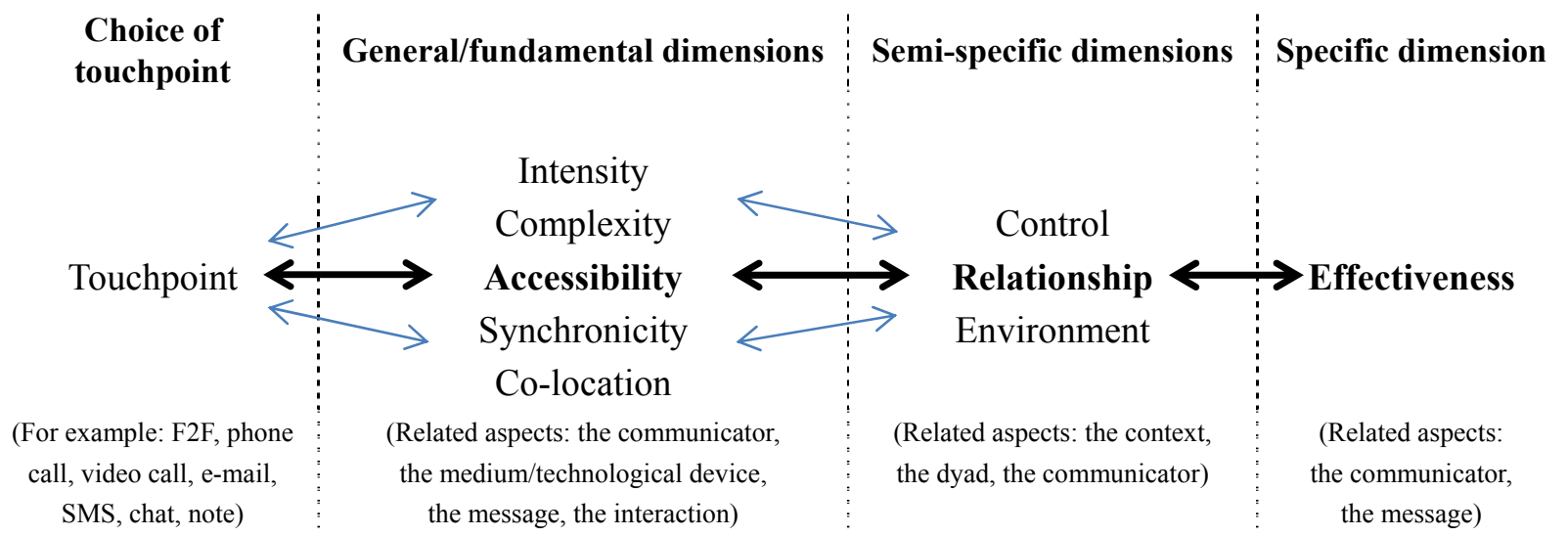

Figure 2. The factors that are affecting the touchpoint management.

A general discussion about medium is a necessary start. There is no real consensus about what medium means. Some mean anything that can transfer a message while others only mean some sort of communication technology. In this paper medium refers only to the particles and waves that directly can affect our sense or send an impulse from one technological device to another. A touchpoint is highly dependent on some media. Even if our minds could use microwaves or where hardwired to each other we would still depend on a medium and that way of getting in touch would also be the touchpoint. The reason why a touchpoint can't be reduced to a medium is because (1) it can rely on several media simultaneously, and (2) a touchpoint has other additional characteristics. A touchpoint can be computer-mediated but it can also exist without any computerized devices or systems being involved. A touchpoint can be artefact based depending on paper and pencil, a message board or a photograph but, on the other hand, it doesn't have to involve any artefacts. A touchpoint can be based on communication aids but it can exist without any of that. Face-to-face without barriers or face-to-face with barriers (especially glass walls or windows) does not involve communication aids. Then again, touchpoints can be face-to-face (with or without barriers) and at the same time involve some kind of technology, and touchpoints can fully rely on communication technology both separately and in combination. A touchpoint is wider in a sense than medium, computer-mediation, technological devices or communication aids but on the other hand it only exists when two minds or more are connected. As soon as the connection is gone the touchpoint is gone but the media, the computers, the communication aids and the technological devices are still there. A touchpoint is something that we create temporarily for special purposes.

The analysis by McLuhan (1964) that every age period has a dominating communication technology might have been true up to his age period but is it true in our time? What is our dominant communication technology? If we look at the number of devices globally it should be the mobile phone (the smartphone). Already when we look closer at this particular device we will find that the statement: "the medium is the message" becomes even more problematic than it was before. A smartphone, if we consider it to be a medium in McLuhans term, can offer a multitude of different kinds of messages. The same goes for the touchpoint. To suggest that the touchpoint is the message is fruitless, especially if we scrutinize an integrated touchpoint. In what way can it be a message? If we still persist that the medium is the message we have to ask ourselves if there might be a (potential/planned) message in the mind of the sender before it is shared. And when the message is received, is the medium also in the receivers mind? How is that possible? No, there is no message out there; it is only in our minds. First only in the sender mind and then also in the receiver mind, if the receiver can interpret it as a message. But, a touchpoint is what makes it possible to connect minds and share messages. Therefore the touchpoint enables the message. If we apply a softer interpretation of McLuhans statement we might say that the touchpoint is affecting the message in the way the goal is attained. The choice of touchpoint and the eventual combination into an integrated touchpoint makes a difference.

The theory of affordances (Gibson, 1986) is relevant to the theory of touchpoint management. The touchpoint has an affordance. The face-to-face touchpoint offers the communicators the possibility to observe the full body of the co-communicator and offers the communicators to use a wide range of production modalities to create a message that is assumed to be perceived by the co-communicator. To Gibson the environment and objects have affordance in relation to the observer/user. If you stand close and face-to-face with a co-communicator you can touch that other person, the present affordance of you plus your co-communicator affords touching, but if you turn around or take two steps back that affordance has changed. Now you can't touch anymore. Gibsons theory includes other beings and tools and is thus still valuable to our understanding of how perception guides action with co-communicators and tools. To the theory of touchpoint management it is of limited value since Gibson didn't want to include intentions (goals) or were particularly 
interested in human-to-human interaction.

Norman (1988) is taking a step further than Gibson in the use and understanding of affordance. People are intentional beings in relation to affordances. This is especially true when you observe a smartphone with almost only smooth surfaces. To know the full potential of the device you have to read the whole manual or have an idea of what you want to do and then try if it is doable. A touchpoint is not only what you obviously can do when you communicate but also what is possible to do even if it might be hidden. The human intentional mind and the ability to be flexible (creative) is setting the limits. Norman (2007) is, influenced by de Souza (2005), pushing the theory of affordances even further. The affordance that you create (as a process of design) has meaning to the receiver/user. First, an affordance is not just something that $i s$, in a static predetermined way, but something that can be created and modified. Second, the way you create or modify the affordance is communicating something about yourself and maybe also your intention. This phenomenon is called affordance as communication. In terms of a touchpoint we create and modify touchpoints and we use touchpoints to communicate who we are and what we want (Holmes, 2005). The management of touchpoints, in kind and degree, is not the message but part of the message in the way that it affects the relationship between communicators and therefore indirectly affects the message.

Media richness theory is centered around classifications of information (uncertain or not, equivocal or not) and different kinds of media (Daft \& Lengel, 1986). The theory prescribes (and predicts) that certain media (rich or lean) is better suited for certain tasks depending on the kind of information. The media richness dimension is defined by four sub dimensions (Sheer, 2011; Walther, 2011): (a) the degree of instant feedback offered; (b) the number of cues offered (also called modalities); (c) the possibility to convey natural languages; (d) the possibility of personalization. Rich media can offer all four. Lean media are restricted in all four dimensions or at least most of them. When relating to touchpoint management, the first dimension is linked both to the degree of closeness in time parameter and the sequence, turn and feedback parameter. The second dimension is linked to sense and production modalities parameters. The third dimension has no equivalent in the touchpoint management theory but might be related to the complexity parameter or the fact that humans are symbol minded. The fourth dimension can be related to touchpoint preference and the discussion about affordance as communication. We will probably choose the kind of touchpoint that reflects our self-identity and personality as a default option. While three out of four dimensions might be influencing factors they still have lesser impact than the dimensions of control, relationship, environment (physical and sociocultural) and effectiveness (goal). The media richness theory is not primarily an interpersonal theory but an organizational communication theory. It is focusing on information and task (see also Sheer \& Chen, 2004, for a developed account of the theory). The originators (Lengel \& Daft, 1984) have also shown an interest in individual differences and their preferences in media type. The touchpoint management theory is focusing on the goal and the interaction with concern for the context (relationship and environmental factors). It is also possible to claim that the media richness theory has a focus on efficiency while the touchpoint management theory has a focus on effectiveness (cf. Leonard et al., 2011).

The media richness theory has been criticized and the need for improvement has led to some new but related theories: Media synchronicity theory, channel expansion theory and media naturalness theory. Media synchronicity theory (Dennis, Valacich, Speier \& Morris, 1998) is based on two dimensions: conveyance (fast/vast exchange of information) and convergence (development of shared meaning). The theory is about having a shared focus in a group or between individuals. This is possible if the parties have the same information available at the same time. Low synchronicity and efficient conveyance is associated with written media while high synchronicity and efficient convergence is associated with face-to-face communication (Dennis, Fuller \& Valacich, 2008). Media synchronicity theory also focus on efficiency instead of effectiveness, opposed to the touchpoint management theory. The development of the theory during the last decade has offered useful insights in general. Channel expansion theory (Carlson \& Zmud, 1999) suggests that it is not only in the medium itself but the knowledge about a medium that influences how rich we perceive it to be. Experience in a certain medium makes it richer to the user than no experience of the medium. This will affect the preference in certain media (see also D’Urso \& Rains, 2008). In terms of a touchpoint this is in line with the suggestion that the accessibility, in this case especially skill and preference, in general will affect what kind of touchpoint(s) we more often choose.

Media Naturalness theory (Kock, 2002; 2005) is an evolutionary inspired theory suggesting that humans have developed to communicate in specific ways. Kock bases his theory on five key elements that characterize face-to-face communication: (a) Co-location that enables us to share context as well as see and hear each other; (b) synchronicity; (c) convey and observe facial expressions; (d) convey and observe body language; (e) convey and listen to speech. When we use media that are outside of this specification, according to the theory, we need to use more cognitive effort to succeed with the communication. There is a kinship between media naturalness theory and touchpoint management theory. The basis for the two theories are the human abilities that make it possible and delimits human communication.

There are some obvious problems with these key elements though. First (c), (d) and (e) could be included in (a). 
Co-location makes the other three possible. If co-location isn't possible but synchronicity (b) is, it could include (c), (d) and (e) if a video call is used. A phone call (b) would include (e). Body language (d), preferably called nonverbal communication, includes facial expressions (c). To suggest otherwise is a huge mistake. What Kock in more specific terms should suggest is that the four key elements of face-to-face communication is characterized by: (1) co-location; (2) synchronicity; (3) vocal verbal communication, and (4) nonverbal communication. If we reduce or delimit any of these four key elements the communication will be more cognitively demanding.

What Kock seem to miss is that humans are intentional beings and highly flexible. It has to be accounted for that humans have the innate ability to be flexible. This flexibility and creativity is making us use tools in a variety of ways. Our intentionality is the guiding light in how we are flexible and how we may use new tools and known tools in new ways. It may be possible that some ways to communicate are less cognitively demanding but it is also typically human, and therefore not as cognitively demanding as it might seem, to develop and learn new ways. Being social minded and imitative means that we easily learn and often want to learn from each other (Noman, 2011).

Cognitive demands, to elaborate on this a bit more, is typically associated with learning to use new tools or to form new habits. To use familiar tools and stick to ones habits is a way to be energy efficient and put low pressure on the cognitive system (Jensen, 2009). This is in advantage of the channel expansion theory (and the accessibility dimension). The tools that we know well are energy efficient and not cognitively demanding. Eventually we tend to learn new things and use new tools. Even if it is associated with cognitive effort it can seem easy if it is something we want to master. Social motivation (inspired by what others master or something that helps gain acceptance in a certain group) as well as intrinsic motivation (a deep personal interest in something specific) is least effortful (Biggs \& Telfer, 1987; Byrnes, 2008; Jordan, Carlile \& Stack, 2008). Learning to use computers and communication devices is for children and adolescents something that seems to be done without any effort (Holmes, 2005).

It is also known that verbal communication, based on symbols, is slower and more cognitively demanding (Allwood, 2008) and that would suggest that nonverbal communication is more efficient from a cognitive effort point of view. To coordinate own verbal and nonverbal cues is reasonably even more demanding than verbal communication alone and to coordinate own and others verbal and nonverbal signs to a conversation has to be a challenge on a higher level (Richardson, Dale \& Shockley, 2008). If co-located and synchronized human communication is the most natural way to communicate, which it undoubtedly is, how can we explain that it also is highly demanding in the actual interaction? Even if it is cognitively demanding it has to have other advantages from an evolutionary perspective like effective goal attainment, cooperation, problem solving, conflict resolution and creation/strengthening of social bonds. Communication is cognitively demanding when we get too little information, too much information or conflicting information. That is what we want to avoid because it can jeopardize the communication effectiveness, cooperation and the stability of social relations.

Social presence theory (see Walther, 2011) is focusing on the experience of someone being present in the other end. Social presence is suggested to mean that we want to feel that we are communicating with a human being and that is most obvious when we communicate face-to-face. The feeling of presence is reduced when we communicate via a phone and even more reduced via written form. Touchpoint management theory emphasize the importance of us being social minded and wanting to be connected and that is creating an apparent bond between the two theories. It should be clarified, though, that connecting minds and being social minded means that we want to be connected with someone or something that we perceive as a mind or can attribute intentionality. This might seem contra intuitive but humans can relate to computers even if the computers have no physical human attributes, and ascribe intentionality, personality, emotions and trust to a computer equally well as to a human (Reeves \& Nass, 1996; Nass, 2012; Holmes, 2005, Frommer et al., 2014). Social information processing theory (SIPT) is suggesting that computer-mediated-communication in a sense is compensating for the lack of nonverbal cues with a stronger emphasize on the written verbal means (linguistic style) and timing. We can create relationships with others based on written mode only. We can even create strong relationships that way. The main difference is that it takes longer time compared to face-to-face interaction (Walther, 2008). SIPT as a theory, in comparison to touchpoint management theory, has low interest in interpersonal communication that isn't computer-mediated and it doesn't include goals.

Media multiplexity theory (Ledbetter, 2015) states that relational ties are the base for communication tool use (or our touchpoint choices). The message shared is primarily affected by the relational tie, not by the kind of tool (touchpoint) used. Dyads with strong ties typically use more communicative tools (touchpoints) than dyads with weak ties do. Stronger ties cause more ways to get in touch and more ways to get in touch cause stronger ties. It also seems that people have favorite ways to get in touch. Some prefer face-to-face while others prefer phone calls and so on. This theory is supportive, in a way, for the touchpoint theory as the multiplexity theory focus on the importance and influence of the relationship and the fact that we use many touchpoints in strong dyads. It also supports the accessibility dimension. 
The strongest support for the touchpoint management theory comes from studies that report serial or integrated touchpoints. Watson-Manheim \& Bélanger (2007) describe the use of serial or integrated touchpoints in organizations. Sheers (2011) study about teenagers' use of Instant messenger shows that teenagers, especially when it comes to self-presentation in friendship development, uses and combines a variety of serial or integrated touchpoints. This behavior suggests that it primarily is effectiveness and secondarily is relationships that drive the management of touchpoints rather than efficiency. If we assume that it is more cognitively demanding to use and coordinate several touchpoints it can't be efficient but it may be the best way to attain the goal. It is more important to attain the goal than to do it with low effort (Leonard et al., 2011). There is always a risk that too low effort might lead to an unattained goal. Dennis, Fuller and Valacich (2008) are also open for the option that combinations can be the best, or actually chosen, way.

The outlined theory of touchpoint management is so far descriptive and explanatory. Not prescriptive. Before specified empirical evidence is at hand the theory can't be predictive either. Maybe never. The theory is primarily an interpersonal communication theory that takes into account the fact that we, in our time, use a large number of different ways to get in touch. This development, more potential touchpoints and new kinds of touchpoint, is something we can most certainly expect also in the future.

\section{References}

Afifi, W. A. (2010a). Nonverbal communication. In Whaley, B. B. \& Samter, W. (eds.) Explaining communication. Contemporary theories and exemplars. London: Routledge.

Afifi, W. A. (2010b). Uncertainty and information management in interpersonal contexts. In Smith, S. W. \& Wilson, S. R. (eds.) New Directions in interpersonal communication research. London: SAGE. http://dx.doi.org/10.4135/9781483349619.n5

Afifi, W. A., \& Weiner, J. L. (2004). Toward a theory of motivated information management. Communication theory, 14, 167-190. http://dx.doi.org/10.1111/j.1468-2885.2004.tb00310.x

Allwood, J. (2008). A Typology of Embodied Communication. In Wachmuth, I., Lenzen, M. \& Knoblich, G. (eds.) Embodied Communication in Humans and Machines. Oxford: Oxford University Press.

Allwood, J. (2014). A framework for studying human multimodal communication. In Rojc, M. \& Campbell, N. (eds.) Coverbal Synchrony in Human-Machine Interaction. Boca Raton, FL: CRC Press, Taylor \& Francis Group. http://dx.doi.org/10.1201/b15477-3

Andersen, P. A., \& Guerrero, L. K. (1998). Principles of Communication and Emotion in Social Interaction. In Andersen, P. A. \& Guerrero, L. K. (eds.). The handbook of communication and emotion: research, theory, applications and contexts. San Diego, CA: Academic Press.

Ansari, A., \& Riasi, A. (2016). An Investigation of Factors Affecting Brand Advertising Success and Effectiveness. International Business Research, 9(4), 20-30. http://dx.doi.org/10.5539/ibr.v9n4p20

Baldwin, D. (2012). Discerning intentions: characterizing the cognitive system at play. In Homer, B. D. \& Tamis-LeMonda, C. S. (eds.). The development of social cognition and communication. London: Psychology Press.

Bandura, A. (1997). Self-efficacy: the exercise of control. New York: Freeman.

Bandura, A. (2001). Social cognitive theory: an agentic perspective. Annu. Rev. Psychol., 52, 1-26. http://dx.doi.org/10.1146/annurev.psych.52.1.1

Bangerten, A., \& Mayor, E. (2013). Interactional theories of communication. In Cobley, P. \& Schulz, P. J. (eds.) Theories and models of communication. Berlin: De Gruyter Mouton.

Bateson, G. (2000). Steps to an ecology of mind. First published in 1972. Chicago: The University of Chicago Press.

Bavelas, J., \& Gerwing, J. (2007). Conversational hand gestures and facial displays in face-to-face dialogue. In K. Fiedler (ed.) Frontiers of Social Psychology: Social Communication. New York: Psychology Press.

Berger, C. (2007). Communication: A goal-directed, plan-guided process. In Roskos-Ewoldsen, D. R. \& Monahan, J. L. (eds.) Communication and social cognition. Theories and methods. London: Lawrence Erlbaum Associates.

Berger, C. (2008). Planning theory of communication. In Baxter, L. A. \& Braithwaite, D. O. (eds.) Engaging theories in interpersonal communication. Multiple perspectives. London: Sage.

Berger, C. (2010). Plans, planning, and communication effectiveness. In Whaley, B. B. \& Samter, W. (eds.) Explaining communication. Contemporary theories and exemplars. London: Routledge. 
Berger, C. R., \& Calabrese, R. J. (1975) Some explorations in initial interaction and beyond: toward a developmental theory of interpersonal communication. Human Communication Theory, 1, 99-112. http://dx.doi.org/10.1111/j.1468-2958.1975.tb00258.x

Biggs, J., \& Telfer, R. (1987). The process of learning. Sydney: Prentice-Hall.

Bolchini, D., \& Shirong, L. A. (2013). Channel. In Cobley, P. \& Schulz, P. J. (eds.) Theories and models of communication. Berlin: De Gruyter Mouton.

Bratman, M. E. (2014). Shared agency. A planning theory of acting together. Oxford: Oxford University Press.

Brown, S., Martinez, M. J., Hodges, D. A., Fox, P. T., \& Parsons, L. M. (2004). The song system of the human brain. Cognitive Brain Research, 20 (3), 363-375. http://dx.doi.org/10.1016/j.cogbrainres.2004.03.016

Burgoon, J. K., Guerrero, L. K., \& Manusov, V. (2011). Nonverbal signals. In Knapp, M. L. \& Daly, J. A. (eds.). The SAGE handbook of interpersonal communication. London: SAGE.

Byrnes, J. P. (2008). Cognitive development and learning. In instructional contexts. Boston: Pearson.

Call. J. (2008). How apes use gestures: the issue of flexibility. In Oller, D. K. \& Griebel, U. (eds.) Evolution of communicative flexibility. Cambridge, MA: The MIT Press. http://dx.doi.org/10.7551/mitpress/9780262151214.003.0011

Canary, D. J., Cody, M. J., \& Manusov, V. L. (2008). Interpersonal communication. A goal-based approach. New York: Bedford / St. Martin's.

Carlson, J. R., \& Zmud, R. W. (1999). Channel Expansion Theory and the Experiential Nature of Media Richness Perceptions. Academy of management journal, 42 (2), 153-170. http://dx.doi.org/10.2307/257090

Cobley, P. (ed.) (2010). The Routledge companion to semiotics. London: Routledge.

D’Urso, S., \& Rains, S. A. (2008). Examining the Scope of Channel Expansion: A Test of Channel Expansion Theory with New and Traditional Communication Media. Management Communication Quarterly, 21(4), 1-20.

Daft, R. L., \& Lengel, R. H. (1986). Organizational information requirements, media richness and structural design. Manegement Science, 32 (5), 554-571. http://dx.doi.org/10.1287/mnsc.32.5.554

de Mooij, M. (2014). Global marketing and advertising. Understanding cultural paradoxes. London: SAGE.

De Souza, C. S. (2005). The semiotic engineering of human-computer interaction. Cambridge, MA: MIT Press.

Deacon, T. W. (1997). The symbolic species. The co-evolution of language and the brain. New York: W. W. Norton \& Company.

Decety, J., \& Chaminade, T. (2005). The neurophysiology of imitation and intersubjectivity. In Hurley, S. \& Chater, N. (eds.) Perspectives on imitation. From neuroscience to social science. Volume 1. London: A Bradford Book.

Delafield-Butt, J. T., \& Trevarthen, C. (2013). Theories of the development of human communication. In Cobley, P. \& Schulz, P. J. (eds.) Theories and models of communication. Berlin: De Gruyter Mouton. http://dx.doi.org/10.1515/9783110240450.199

Dennis, A. R., Fuller, R. M., \& Valacich, J. S. (2008). Media, Tasks, and Communication Processes: A Theory of Media Synchronicity. MIS Quarterly, 32(3), 575-600.

Dennis, A. R., Valacich, J. S., Speier C., \& Morris, M. G. (1998). Beyond Media Richness: An Empirical Test of Media Synchronicity Theory. System Sciences, Proceedings of the Thirty-First Hawaii International Conference, 1, 48-57. http://dx.doi.org/10.1109/HICSS.1998.653082

Dhebar, A. (2013). Toward a compelling customer touchpoint architecture. Business Horizons, 56(2), 199-205. http://dx.doi.org/10.1016/j.bushor.2012.11.004

Dillard, J. P. (2008). Goals-plans-action theory of message production. In Baxter, L. A. \& Braithwaite, D. O. (eds.) Engaging theories in interpersonal communication. Multiple perspectives. London: Sage.

Dunbar, R. (2007a). The social brain hypothesis and its relevance to social psychology. In Forgas, J. P., Haselton, M. G. \& von Hippel, W. (eds.) Evolution and the social mind. Evolutionary psychologi and social cognition. New York: Psychology press.

Dunbar, R. (2007b). Evolution of the social brain. In Gangestad, S. W. \& Simpson, J. A. (eds.). The evolution of mind. Fundamental questions and controversies. London: The Guilford press.

Ekman, P., \& Friesen, W. V. (1981). The repertoire of nonverbal behavior: categories, origins, usage, and coding. First 
published in 1967. In Kendon, A. (ed.) Nonverbal communication, interaction, and gesture. The Hague: Mouton Publishers. http://dx.doi.org/10.1515/9783110880021.57

Elias, S. (1999). Sound marketing in the age of experience. Design management journal, 10 (1), 68-74. http://dx.doi.org/10.1111/j.1948-7169.1999.tb00244.x

Forgas, J. P., Vincze, O., \& László, J. (2014). Social cognition and communication. London: Psychology Press.

Forgas, J. P., Williams, K. D., \& Wheeler, L. (eds.) (2001). The social mind. Cognitive and motivational aspects of interpersonal behavior. Cambridge, UK: Cambridge University Press.

Frank, M. G., \& Svetieva, E. (2013). Deception. In Matsumoto, D., Frank, M. G. \& Hwang, H. S. (eds.) Nonverbal communication. Science and applications. London: SAGE. http://dx.doi.org/10.4135/9781452244037.n6

Frommer, J., Rösner, D., Lange, J., \& Haase, M. (2014). Giving computers personality? Personality in computers is in the eye of the user. In Rojc, M. \& Campbell, N. (eds.) Coverbal Synchrony in Human-Machine Interaction. Boca Raton, FL: CRC Press, Taylor \& Francis Group. http://dx.doi.org/10.1201/b15477-4

Gardner, H. (1985). The mind's new science. New York: Basic Books.

Gazzaniga, M. S. (2008). Human. The science behind what makes us unique. New York: HarperCollins.

Gibbs, R. W. (1999). Intentions in the experience of meaning. New York: Cambridge university press.

Gibbs, R. W. (2001). Intentions as emergent products of social interactions. In Malle, B. F., Moses, L. J. \& Baldwin, D. A. (eds.) Intentions and intentionality. Foundations of social cognition. Cambridge, MA: A Bradford Book.

Gibson, J. J. (1986). The ecological approach to visual perception. Hillsdale, NJ: Lawrence Erlbaum Associates.

Giles, H., \& Soliz, J. (2015). Communication accommodation theory: A situated framework for relational, family, and intergroup dynamics. In Braithwaite, D. O. \& Schrodt, P. (eds.) Engaging theories in interpersonal communication. Multiple perspectives. Second edition. London: SAGE.

Goldman, A. I. (2006). Simulating minds. Oxford: Oxford University Press. http://dx.doi.org/10.1093/0195138929.001.0001

Goldman, A. I. (2013). Joint ventures. Oxford: Oxford University Press. http://dx.doi.org/10.1093/acprof:osobl/9780199874187.001.0001

Goldsmith, D. J. (2008). Politeness theory. In Baxter, L. A. \& Braithwaite, D. O. (eds.) Engaging theories in interpersonal communication. Multiple perspectives. London: Sage.

Gottlieb, J., Oudeyer, P. Y., Lopes, M., \& Baranes, A. (2013). Information-seeking, curiosity, and attention: computational and neural mechanisms. Trends in cognitive sciences, 17(11), 585-593.

http://dx.doi.org/10.1016/j.tics.2013.09.001

Greene, J. O. (2015). Action assembly theory: Forces of creation. In Braithwaite, D. O. \& Schrodt, P. (eds.) Engaging theories in interpersonal communication. Multiple perspectives. Second edition. London: SAGE. http://dx.doi.org/10.4135/9781483329529.n2

Greene, J. O., \& Dorrance Hall, E. (2013). Cognitive theories of communication. In Cobley, P. \& Schulz, P. J. (eds.). Theories and models of communication. Berlin: De Gruyter Mouton. http://dx.doi.org/10.1515/9783110240450.181

Grice, H. P. (1957). Meaning. The Philosophical Review, 66 (3), 377-388. http://dx.doi.org/10.2307/2182440

Grice, H. P. (1969). Utterer's meaning and intention. The Philosophical Review, 78 (2), 147-177.

Griebel, U., \& Oller, D. K. (2008). Evolutionary forces favoring communicative flexibility. In Oller, D. K. \& Griebel, U. (eds.). Evolution of communicative flexibility. Cambridge, MA: The MIT Press. http://dx.doi.org/10.7551/mitpress/9780262151214.003.0002

Gurban, M., \& Thiran, J. P. (2010). Basic concepts of multimodal analysis. In Thiran, J-P., Marqués, F. \& Bourlard, H. (eds.) Multimodal signal processing. Theory and applications or human-computer interaction. London: Academic Press. http://dx.doi.org/10.1016/B978-0-12-374825-6.00016-2

Hall, E. T. (1969). The hidden dimension. New York: Anchor Books.

Hauser, M. D., \& Santos, L. R. (2007). The evolutionary ancestry of our knowledge of tools: from percepts to concepts. In Margolis, E. \& Laurence, S. (eds.) Creations of the mind. Theories of artifacts and their representations. Oxford: Oxford university press. 
Hollingshead, A. B., Costa, J. G., \& Beck, S. J. (2007). Motives and goals in context: A strategic analysis of information sharing in groups. In K. Fiedler (ed.) Frontiers of Social Psychology: Social Communication. New York: Psychology Press.

Holmes, D. (2005). Communication theory. Media, technology and society. London: SAGE.

Hurley, S. (2005). The shared circuits hypothesis: a unified functional architecture for control, imitation, and simulation. Hurley, S. \& Chater, N. (eds.) Perspectives on imitation. From neuroscience to social science. Volume 1. London: A Bradford Book.

Hurley, S., \& Chater, N. (eds.) (2005) Perspectives on imitation. From neuroscience to social science. Volume 1. London: A Bradford Book.

Iacoboni, M. (2009). Mirroring people. The science of empathy and how we connect with others. New York: Picador. Jackendoff, R. (2009). Language, consciousness, culture. Essays on mental structure. London: A Bradford book.

Jensen, M. (2009). Lifestyle: Suggesting mechanism and a definition from a cognitive science perspective. Environment, Development and Sustainability, 11 (1), 215-228. http://dx.doi.org/10.1007/s10668-007-9105-4

Jensen, M. (2015a). Smile as Feedback Expressions in Interpersonal Interaction. International Journal of Psychological Studies, 7 (4), 95-105. http://dx.doi.org/10.5539/ijps.v7n4p95

Jensen, M. (2015b). Interpersonell kommunikation. Lund: Studentlitteratur.

Jensen, M. (2016a). Touchpoints, Time and Dyads: A case of Internal Organizational Communication. International Journal of Multidisciplinary Academic Research, 4 (2), 21-33.

Jensen, M. (2016b). Personality Traits and Nonverbal Communication Patterns. International Journal of Social Science Studies, 4 (5), 57-70. http://dx.doi.org/10.11114/ijsss.v4i5.1451

Jordan, A., Carlile, O., \& Stack, A. (2008). Approaches to learning. A guide for teachers. Beckshire, UK: Open University Press.

Kashima, Y., Klein, O., \& Clark, A. E. (2007). Grounding: sharing information in social interaction. In K. Fiedler (ed.) Frontiers of Social Psychology: Social Communication. New York: Psychology Press.

Kendon, A. (1981). Introdution: Current issues in the study of nonverbal communication. In Kendon, A. (ed.) Nonverbal communication, interaction, and gesture. The Hague: Mouton Publishers.

Kendon, A. (2004). Gesture. Visible action as utterance. Cambridge, UK: Cambridge University Press. http://dx.doi.org/10.1017/CBO9780511807572

Kinsbourne, M. (2005). Imitations as entrainment. In Hurley, S. \& Chater, N. (eds.) Perspectives on imitation, 2. London: A Bradford Book.

Knapp, M. L., \& Vangelisti, A. L. (2009). Interpersonal Communication and Human Relationships. Boston, MA: Allyn \& Bacon.

Knobloch, L. K. (2008). Uncertainty reduction theory. In Baxter, L. A. \& Braithwaite, D. O. (eds.) Engaging theories in interpersonal communication. Multiple perspectives. London: Sage.

Kock, N. (2002). Evolution and media naturalness: a look at e-communication through a Darwinian theoretical lens. Twenty-Third International Conference on Information Systems.

Kock, N. (2005). Media Richness or Media Naturalness? The Evolution of Our Biological Communication Apparatus and Its Influence on Our Behavior Toward E-Communication Tools. IEEE Transactions on professional communication, 48(2), 117-130. http://dx.doi.org/10.1109/TPC.2005.849649

Krauss, R. M., \& Morsella, E. (2014). Communication and conflict. In Coleman, P. T., Deutsch, M. \& Marcus, E. C. (eds.). The handbook of conflict resolution. Theory and practice. San Francisco: Jossey-Bass.

Kress, G. (2010). Multimodality. A social semiotic approach to contemporary communication. New York: Routledge.

Lane, W., \& Manner, C. (2011). The Impact of Personality Traits on Smartphone Ownership and Use. International Journal of Business and Social Science, 2(17), 22-28.

Ledbetter, A. M. (2015). Media multiplexity theory: technology use and interpersonal tie strength. In Braithwaite, D. O. \& Schrodt, P. (eds.) Engaging theories in interpersonal communication. Multiple perspectives. Second edition. London: SAGE.

Lee, K., Chung, K. W., \& Nam, K. Y. (2013). Orchestrating designable touchpoints for service businesses. Design 
management review, 24 (3), 14-21. http://dx.doi.org/10.1111/drev.10246

Lengel, R. H., \& Daft, R. L. (1984). Organizations as information processing systems. An Exploratory Analysis of the Relationship Between Media Richness and Managerial Information Processing. Office of Naval Research Technical Report Series, TR-ONR-DG-08. Department of Management Texas A\&M University.

Leonard, K. et al. (2011). Examining media effectiveness across cultures and national borders: A review and multilevel framework. International Journal of Cross Cultural Management, 11 (1), 83-103.

Liebal, K., Waller, B. M., Burrows, A. M., \& Slocombe, K. E. (2014). Primate communication. A multimodal approach. Cambridge: Cambridge University Press.

Lo, S. H., \& Lie, T. (2008). Selection of communication technologies-A perspective based on information richness theory and trust. Technovation, 28, 146-153.

MacLeod, C. M. (2007). The concept of inhibition in cognition. In Gorfein, D. S. \& MacLeod, C. M. (eds.) Inhibition in cognition. Washington, DC: American Pychological Association. http://dx.doi.org/10.1037/11587-001

Malle, B. F. (2005). Three puzzles of mindreading. In Malle, B. F. \& Hodges, S. D. (eds.) Other minds. New York: The Guilford Press.

Marios, R., \& Ivanoff, J. (2005). Capacity limits of information processing in the brain. Trends in cognitive sciences, 9(6), 296-305. http://dx.doi.org/10.1016/j.tics.2005.04.010

Matsumoto, D. (ed.) (2010). APA handbook of interpersonal communication. Washington, DC: American Pychological Association.

Matsumoto, D., \& Hwang, H. S. (2013). Facial expressions. In Matsumoto, D., Frank, M. G. \& Hwang, H. S. (eds.) Nonverbal communication. Science and applications. London: SAGE. http://dx.doi.org/10.4135/9781452244037.n2

McCrae, R. R., \& Costa, P. T. (2006). Personality in adulthood. A five-factor theory perspective. London: The Guilford Press.

McCroskey, J. C., \& Beatty, M. J. (1998). Communication apprehension. In McCroskey, J. C., Daly, J. A., Martin, M. M. $\&$ Beatty, M. J. (eds.) Communication and personality. Trait perspectives. Cresskill, NJ: Hampton Press inc.

McLuhan, M. (1964). Understanding media. The extensions of man. New York: the MIT Press.

Meltzoff, A. N. (1988). Infant imitation after a 1-week delay: Long-term memory for novel acts and multiple stimuli. Developmental Psychology, 24(4), 470-476. http://dx.doi.org/10.1037/0012-1649.24.4.470

Meltzoff, A. N. (1995). Understanding the intentions of others: Re-enactment of intented acts by 18 -month-old children. Developmental Psychology, 31 (5), 838-850. http://dx.doi.org/10.1037/0012-1649.31.5.838

Meltzoff, A. N. (2005). Imitation and other minds: the "like me" hypothesis. In Hurley, S. \& Chater, N. (eds.) Perspectives on imitation, 2. London: A Bradford Book.

Meltzoff, A. N., \& Prinz, W. (eds.) (2002). The imitative mind. Development, evolution, and brain bases. Cambridge, UK: Cambridge University Press.

Miller, K. (2015). Organizational communication. Approaches and processes. Stamford, CT: Cengage Learing.

Namy, L. L., \& Waxman, S. R. (2005). Symbols redefined. In Namy, L. L. (ed.) Symbol use and symbolic representation: Developmental and comparative perspectives. Mahwah, NJ: Lawrence Erlbaum Associates.

Nass, C. (2012). The man who lied to his laptop. New York: Current.

Newell, A., \& Simon, H. A. (1972). Human problem solving. Engelwood Cliffs, NJ: Prentice-Hall.

Norman, D. A. (1988). The design of everyday things. New York: Basic books.

Norman, D. A. (1999). The invisible computer. Cambridge, MA: The MIT Press.

Norman, D. A. (2007). The design of future things. New York: Basic books.

Norman, D. A. (2011). Living with complexity. Cambridge, MA: The MIT Press.

Norris, S. (2004). Analyzing multimodal interaction. A methodological framework. London: Routledge.

Oberzaucher, E., \& Grammer, K. (2008). Everything is movement: on the nature of embodied communication. In Wachmuth, I., Lenzen, M. \& Knoblich, G. (eds.) Embodied Communication in Humans and Machines. Oxford: Oxford University Press. http://dx.doi.org/10.1093/acprof:oso/9780199231751.003.0008 
Paivio, A. (2007). Mind and its evolution. A dual coding theoretical approach. London: Lawrence Erlbaum Associates.

Pandzic, I. S. (2010). Multimodal HCI output: facial motion, gestures and synthesized speech synchronization. In Thiran, J-P., Marqués, F. \& Bourlard, H. (eds.) Multimodal signal processing. Theory and applications or human-computer interaction. London: Academic Press.

Partan, S., \& Marler, P. (2005). Issues in the classification of multimodal communication signals. The American Naturalist, 166 (2), 231-245. http://dx.doi.org/10.1086/431246

Perice, C. S. (1998). The Essential Peirce. Selected philosophical writings. Vol. 2, 1893-1913. Bloomington, IN: Indiana University Press.

Perrin, D., \& Ehrensberger-Dow, M. (2010). Media competence. In Matsumoto, D. (ed.) APA handbook of interpersonal communication. Washington, DC: American Pychological Association.

Proulx, M. J. (2007). The strategic control of attention in visual search. Top down and bottom-up processes. Saarbrücken: VDM verlag Dr. Müller.

Puccinelli, N. M. (2010). Nonverbal communicative competence. In Matsumoto, D. (ed.) APA handbook of interpersonal communication. Washington, DC: American Pychological Association.

Reeves, B., \& Nass, C. (1996). The media equation. New York: Cambridge University Press.

Riasi, A., \& Amiri, A. S. F. (2013). Effects of a Hypothetical Iranian Accession to the World Trade Organization on Iran's Flower Industry. Consilience: The Journal of Sustainable Development, 10(1), 99-110. http://dx.doi.org/10.7916/D8HQ3ZK8

Riasi, A., \& Pourmiri, S. (2015). Effects of online marketing on Iranian ecotourism industry: Economic, sociological, and cultural aspects. Management Science Letters, 5(10), 915-926. http://dx.doi.org/10.5267/j.msl.2015.8.005

Richardson, D. C., Dale, R., \& Shockley, H. (2008). Synchrony and swing in conversation: coordination, temporal dynamics, and communication. In Wachmuth, I., Lenzen, M. \& Knoblich, G. (eds.) Embodied Communication in Humans and Machines. Oxford: Oxford University Press.

http://dx.doi.org/10.1093/acprof:oso/9780199231751.003.0004

Rogers, E. M. (2003). Diffusion of innovation. New York: Free Press.

Ruiz, N., Chen, F., \& Oviatt, S. (2010). Multimodal human-computer and human-to-human interaction. In Thiran, J-P., Marqués, F. \& Bourlard, H. (eds.) Multimodal signal processing. Theory and applications or human-computer interaction. London: Academic Press.

Sabbagh, M. A., \& Baldwin, D. (2005). Understanding the role of communicative intentions in word learning. In Eilan, N., Hoerl, C., McCormack, T. \& Roessler, J. (eds.) Joint attention: communication and the other minds. Oxford: Clarendon Press. http://dx.doi.org/10.1093/acprof:oso/9780199245635.003.0008

Salem, P. (2009). The complexity of human communication. Cresskill, NJ: Hampton Press.

Searle, J. R. (1969). Speech acts. Cambridge: Cambridge University Press. http://dx.doi.org/10.1017/CBO9781139173438

Shannon, C. E., \& Weaver, W. (1949). The mathematical theory of communication. Urbana, Ill.: University of Illinois Press.

Sheer, V. C. (2011). Teenagers' Use of MSN Features, Discussion Topics, and Online Friendship Development: The Impact of Media Richness and Communication Control. Communication Quarterly, 59(1), 82-103. http://dx.doi.org/10.1080/01463373.2010.525702

Sheer, V. C., \& Chen, L. (2004). Improving media richness theory. Management Communication Quarterly, 18(1), 76-93.

Spengler, C., \& Wirt, W. (2009). Maximising the impact of marketing and sales activities. io new management, 3, 1-5.

Sperber, D., \& Wilson, D. (1995). Relevance. Communication \& cognition. Oxford: Blackwell Publishing.

Stephan, A., Lenzen, M., Call, J., \& Uhl, M. (2008). Communication and cooperation in living beings and artificial agents. In Wachmuth, I., Lenzen, M. \& Knoblich, G. (eds.) Embodied Communication in Humans and Machines. Oxford: Oxford University Press. http://dx.doi.org/10.1093/acprof:oso/9780199231751.003.0009

Tomasello, M. (2003). The cultural origins of human cognition. London: Harvard University Press.

Tomasello, M. (2005). Constructing a language: a usage-based theory of language acquisition. Cambridge, Mass.: Harvard Univ. Press. 
Tomasello, M. (2008). Origins of human communication. Cambridge, MA: MIT Press.

Tomasello, M. et al. (2005). Understanding and sharing intentions: The origins of cultural cognition. Behavioral and Brain Sciences, 28, 675-691. http://dx.doi.org/10.1017/S0140525X05000129

Tomasello, M., \& Carpenter, M. (2005). Intention reading and imitative learning. In Hurley, S. \& Chater, N. (eds.) Perspectives on imitation. From neuroscience to social science. Vol 2. London: A Bradford Book.

Trevarthen, C., \& Aitken, K. (2003). Regulation of brain development and age-related changes in infants' motives: The developmental function of regressive periods. In Heimann, M. (ed.) Regression Periods in Human Infancy. Mahwah, NJ: Erlbaum.

Walker-Andrews, A. (2012). Perceiving social affordances: The development of emotional understanding. In Homer, B. D. \& Tamis-LeMonda, C. S. (eds.) The development of social cognition and communication. London: Psychology Press.

Walther, J. B. (2008). Social information processing theory. In Baxter, L. A. \& Braithwaite, D. O. (eds.) Engaging theories in interpersonal communication. Multiple perspectives. London: Sage.

Walther, J. B. (2011). Theories of computer-mediated communication and interpersonal relations. In Knapp, M. L. \& Daly, J. A. (eds.) The SAGE handbook of interpersonal communication. London: SAGE.

Watson-Manheim, M. B., \& Bélanger, F. (2007). Communication Media Repertoires: Dealing with the Multiplicity of Media Choices. MIS Quarterly, Vol 31 (2), 267-293.

Wharton, T. (2013). Linguistic action theories of communication. In Cobley, P. \& Schulz, P. J. (eds.). Theories and models of communication. Berlin: De Gruyter Mouton. http://dx.doi.org/10.1515/9783110240450.241

Whiten, A. (2007). The place of 'deep social mind' in the evolution of human nature. In Pasternak, C. (ed.). What makes us human? Oxford: A Oneworld book.

Wilden, A. (1987). The rules are no game. The strategy of communication. London: Routledge.

Wilson, S. R. (2010). Communication theory and the concept of "goal". In Whaley, B. B. \& Samter, W. (eds.). Explaining communication. Contemporary theories and exemplars. London: Routledge.

Young, R. O. (2011). How audiences decide. A cognitive approach to business communication. London: Routledge.

Zegarac, V. (2011). A cognitive pragmatic perspective on communication and culture. In Matsumoto, D. (ed.) APA Handbook of intercultural communication. Washington, DC: American Pychological Association.

This work is licensed under a Creative Commons Attribution 3.0 License. 